$10-2002$

\title{
Relative Strengths of Competition for Space and Food in a Sessile Filter Feeder
}

David P. Lohse

Virginia Institute of Marine Science

Follow this and additional works at: https://scholarworks.wm.edu/vimsarticles

Part of the Terrestrial and Aquatic Ecology Commons, and the Zoology Commons

\section{Recommended Citation}

Lohse, David P., "Relative Strengths of Competition for Space and Food in a Sessile Filter Feeder" (2002). VIMS Articles. 1687.

https://scholarworks.wm.edu/vimsarticles/1687

This Article is brought to you for free and open access by W\&M ScholarWorks. It has been accepted for inclusion in VIMS Articles by an authorized administrator of W\&M ScholarWorks. For more information, please contact scholarworks@wm.edu. 


\title{
Relative Strengths of Competition for Space and Food in a Sessile Filter Feeder
}

\author{
DAVID P. LOHSE \\ Virginia Institute of Marine Science, Gloucester Point, Virginia 23062; and *Department of Ecology \\ and Evolutionary Biology, Long Marine Laboratory, University of California, \\ Santa Cruz, 100 Shaffer Road, Santa Cruz, California 95060
}

\begin{abstract}
Previous workers have demonstrated that sessile filter feeders compete for food and space, but little is known about the relative strengths of these two processes. To determine this, the density and position of barnacles (Balanus improvisus) in a unidirectional current were manipulated to alter the amount of competition for space and food, respectively. Results indicated that competition for space significantly reduced growth, and marginally reduced survivorship. Competition for food was also detected, but only among uncrowded individuals; thus, it appears to be the weaker of the two interactions. However, under crowded conditions, downstream individuals actually grew more than those upstream. The most likely explanation for this result is that downstream individuals fed more efficiently because they were not exposed to the full force of the current. The results also suggest that since natural densities started high but continually decreased throughout the study, barnacles undergo an ontogenetic shift in the relative importance of these processes.
\end{abstract}

\section{Introduction}

Because all organisms need a place to live, it is not unreasonable for ecologists to consider competition for space a potentially important interaction. However, for some organisms access to space is inherently linked with access to other resources. For example, for terrestrial plants, access to space also involves access to water, light, and nutrients (Grime, 1979). Similarly, Buss (1979) argued that for sessile filter feeders, access to food depends, in part, on access to space. Although much is known about the role of competition for space on rocky shores (e.g., Connell, 1961a, b; Menge, 1976; Wu, 1980; Bertness, 1989), little is known

Received 8 June 2001; accepted 3 July 2002.

* Current address. E-mail: lohse@biology.ucsc.edu about the importance of competition for food. At one time it was even suggested that filter feeders do not compete for food (Levinton, 1972), but an established and growing body of evidence indicates that they in fact do (Crisp and Davies, 1955; Crisp, 1964; Glynn, 1973; Buss, 1979; Jorgensen, 1980; Buss and Jackson, 1981; Peterson, 1982; Peterson, 1983; Frechette and Bourget, 1985; Okamura, 1986; Page and Hubbard, 1987; Peterson and Black, 1987; Newell, 1990; Prins et al., 1995).

For sessile filter feeders, competition for space and competition for food are mechanistically different. Competition for space, where neighbors overgrow or undercut each other, is interference competition. Competition for food, which occurs when upstream individuals take food away from those downstream, is exploitation competition. Therefore, a logical question is, What are the relative strengths of these two processes? Few studies have dealt with both competition for space and food, so little information is available to answer this question. Frechette and Lefaivre (1990) concluded that the relative importance of these processes varies seasonally. Frechette and Despland (1999), however, concluded that, for small mussels at low densities, competition for food was more important. Cote et al. (1994) reached a similar conclusion for scallops, but a problem with their statistical analysis raises questions about this result. Best and Thorpe (1986) and Frechette et al. (1992) considered both processes, but did not assess their relative strengths.

This study assesses the relative strengths of exploitation and interference competition for a sessile filter feeder. Specifically, the question addressed was, Do immediate neighbors compete more for space or food? To answer this question, barnacles were induced to settle in rows on rectangular panels, and densities on half of the panels were 
reduced to test for competition for space. The panels were then deployed in a unidirectional current, and the growth and survivorship of upstream and downstream individuals were compared to test for competition for food. Food availability was not directly manipulated, but half of the panels were rotated weekly to change the position of the upstream and downstream individuals. By altering the barnacles' position in the current, this change potentially altered their food supply.

\section{Materials and Methods}

This study was conducted from May to July 1993 at the Virginia Institute of Marine Science, located at the mouth of the York River, Virginia. Because the York River is a tributary of the Chesapeake Bay, there are twice daily reversals in the direction of the water flow coincident with the tidal cycle. The tides here are semidiurnal, and the tidal range is about -0.2 to $0.9 \mathrm{~m}$ (mean low water). Maximum current speed is about $50 \mathrm{~cm} / \mathrm{s}$ in the center of the river, but is lower near the shore. During the study the water temperature ranged from 25 to $27^{\circ} \mathrm{C}$, and the salinity from 15 to 21 ppt.

The common rocky shore organisms in the intertidal region at this site are the barnacles Balanus improvisus, $B$. eberneus, and Chthamalus fragilis, and the oyster Crassostrea virginica. Only B. improvisus was used in this experiment. Midway through the study the hydroid Hydractinia spp. appeared and overgrew everything, making it necessary to scrub the panels used (see below) every week to keep them free of this organism. The predatory flatworm Stylochus spp. was also consistently found on the panels and probably contributed to the mortality observed during the study.

\section{Experimental setup}

In early May 1993, $6 \times 20 \mathrm{~cm}$ settlement panels were constructed of 4-mm acrylic plastic. Because barnacles preferentially settle in depressions (Crisp and Barnes, 1954), five shallow grooves, $1-2 \mathrm{~mm}$ deep and $1 \mathrm{~cm}$ apart, were cut down the length of each panel to induce settlement. The edges of the panels were beveled to minimize problems with boundary-layer detachment (see Mullineaux and Butman, 1991; Mullineaux and Garland, 1993). Plastic cable ties were used to attach the panels to wooden blocks that were also beveled at one end (Fig. 1), and the blocks were deployed at two locations on a pier owned by the institute. To suspend the panels from the pier, a rope was passed through a hole drilled through the top of each block (Fig. 1). Twelve panels (six wooden blocks) were placed about $150 \mathrm{~m}$ offshore (site A), and ten panels (five wooden blocks) were deployed about $50 \mathrm{~m}$ offshore (site B) where the current was slower (unpubl. data). All the panels were placed at about $-0.1 \mathrm{~m}$ (mean low water).

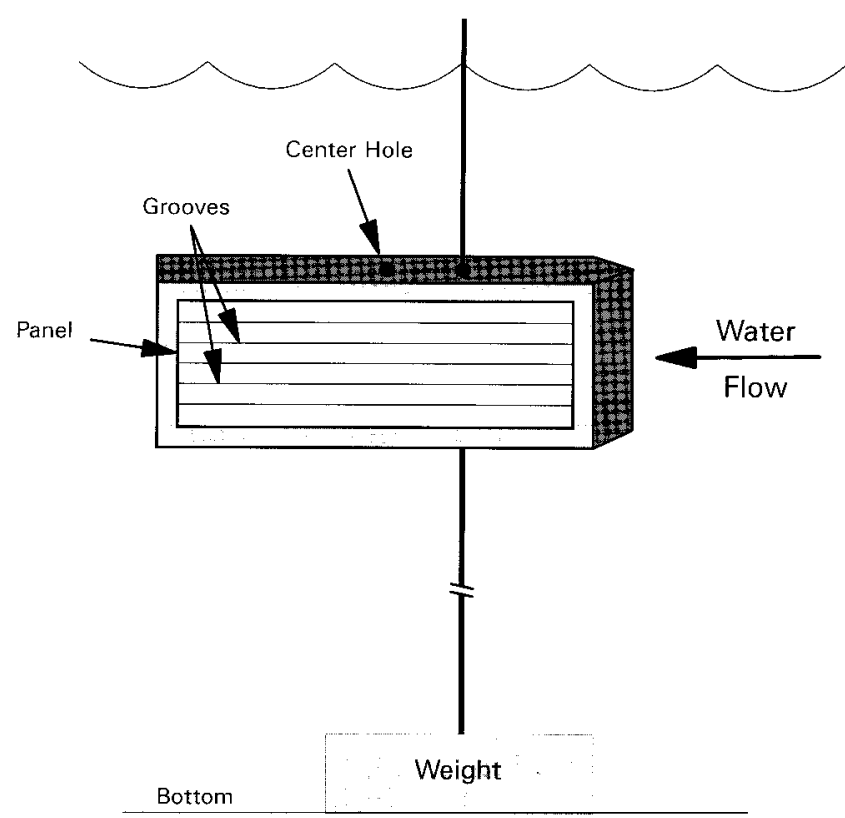

Figure 1. The experimental setup. The panels were attached to wooden blocks that had two holes drilled through their tops, one midway down the block and the other several centimeters towards the front. Initially, when the panels were deployed to collect recruits, the ropes used to suspend the blocks from the pier were passed through the center hole. This allowed the blocks to rotate freely with the current. During the experiment, however, the rope was placed through the forward-most hole. Just like a weather vane, this kept the front (beveled end) of the blocks always pointed upstream. To prevent the ropes from swaying with the current, the bottoms of the ropes were attached to concrete blocks. These blocks rested on the bottom so the ropes could be pulled taut.

The panels were checked weekly for recruitment, and any barnacles that settled outside of the grooves were removed. Once the grooves were filled with barnacles, all the panels were removed from the blocks and randomly assigned to one of two treatments, uncrowded or crowded. The barnacles on the uncrowded panels were thinned (mean $=1.2$ barnacles per linear $\mathrm{cm}, \mathrm{SE}=0.02, n=56$ ) so they could grow without touching. Nothing was done to the crowded panels, so densities started out higher (mean $=4.4$ barnacles per linear $\mathrm{cm}, \mathrm{SE}=0.08, n=56$ ), and adjacent barnacles touched one another. Any new barnacles settling on the panels after this point were removed.

After designating one end of each panel as the front, 4 (uncrowded) to 7 (crowded) barnacles in each groove at the front, middle, and back of the panels (for a total of 12-21 individuals per row) were "marked" by mapping their positions onto sheets of clear acetate. The opercular diameter of these individuals was measured to the nearest $0.1 \mathrm{~mm}$, using a dissecting scope with an ocular micrometer. The panels were then reattached to the wooden blocks with the front of the panels at the front (the beveled end) of the block, and the blocks were deployed as before, with one exception. This time the ropes used to suspend the blocks 


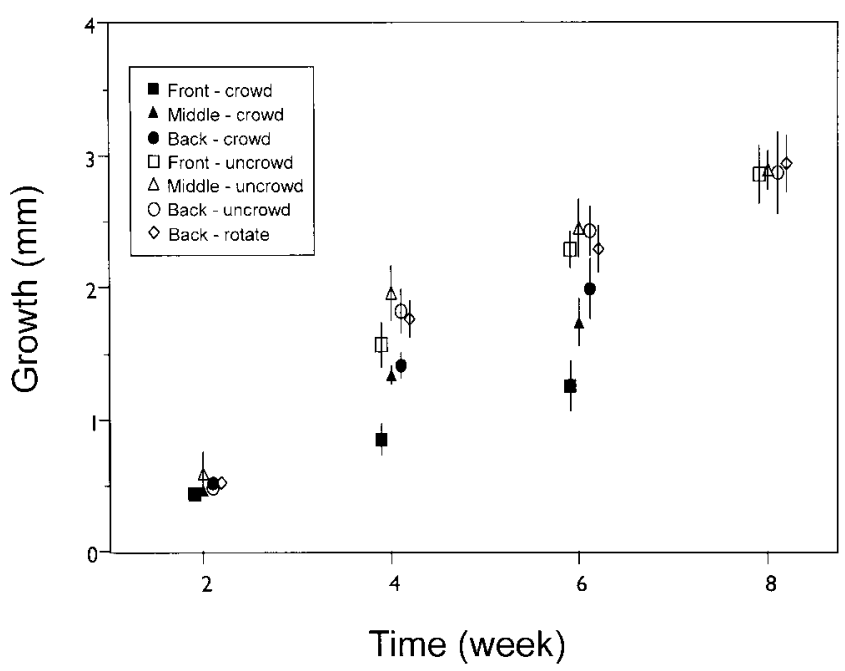

Figure 2. Mean growth $( \pm 1 \mathrm{SE})$ of the barnacles in the different treatments on the panels. In some cases error bars are smaller than the symbol.

were placed in a hole that was closer to the front of the block (Fig. 1). This caused the block to act like a weather vane, with its front always pointing upstream. Therefore, barnacles at the front had first access to food, while those at the back fed in water that had passed over all the individuals upstream of them. Thus, those at the back should grow more slowly if there is competition for food. Meanwhile, those on the crowded panels should grow more slowly if there is competition for space. Four crowded and eight uncrowded panels were deployed at site A, and three crowded and six uncrowded panels were deployed at site B.

As an additional test for food competition, half of the panels in the low-density treatment were rotated every week so that the front and back of the panels switched places on the blocks. "Back" individuals on these panels spent half their time at the front of the blocks, with no barnacles upstream of them, and half the time at the back, with many barnacles upstream of them. In contrast, back individuals on the nonrotated panels had barnacles upstream of them all of the time. Therefore, back individuals on the rotated panels had, on average, fewer barnacles upstream of them and, thus, potentially more food available to them than those on the non-rotated panels. Since rotating the panels also altered the position of the rows, every week the non-rotated panels were removed and reattached to the opposite sides of the blocks. This altered the position of the rows, but not the location of the front and back of the panels.

Every 2 weeks, individuals were remeasured and maps were made of all the living barnacles on each panel. These maps were used to determine how many barnacles were upstream of each measured individual during each 2-week interval. The experiment was terminated after week 8 .
Analyses

Two a priori expectations dictated how the data were analyzed. First, because they were thinned out, the barnacles on the uncrowded panels could not compete for space. Therefore, the effects of competition for space were examined by comparing crowded and uncrowded individuals at the front of the non-rotated panels. Second, since barnacles feed by trapping particles in their cirral net as water passes over them, there is no way for downstream individuals to take food from upstream individuals. Thus, barnacles at the front of the panels could not experience competition for food. Therefore, the effects of competition for food were examined by comparing individuals at the front and back of the uncrowded, non-rotated panels. Rotation, which placed back individuals at the front of the blocks for half of the time, was expected to increase growth compared to back individuals on the nonrotated panels.

Two-way ANCOVA was used to look for the effects of competition for space on growth. Treatment (crowded vs. uncrowded) and site (higher vs. lower current) were fixed factors, and initial size of the barnacle was used as the covariate. Only those at the front of the non-rotated panels were used, to avoid any confounding problems with competition for food. Separate analyses were performed for the first three periods (weeks $0-2,0-4,0-6$ ), but none was done for the last (week $0-8$ ) because virtually all barnacles had become uncrowded by week 6 . Although several individuals within each row were measured, it was the panels that were considered replicates. Therefore, prior to analysis a single growth measurement was determined for each panel as follows. First, the average growth for each row was calculated, then a weighted average was taken of the five row means on each panel, using the number of individuals in each row as a weighting factor. The same was done to determine the value of the covariate (initial size) for each panel. As necessary, crowded barnacles (defined as those that, within a row, touched their neighbors on both sides) that became uncrowded were eliminated from the analyses.

Since growth at the back of the panels was potentially dependent upon how much growth took place at the front, ANCOVA was not used to test for competition for food because an underlying assumption of this test is that treatments are independent. Instead, two different analyses were used. First, a paired $t$ test was used to compare the difference in growth measured at the front and back of the panels against a value of zero. Only the non-rotated panels were used for this analysis, and separate analyses were done for each interval (weeks $0-2,0-4,0-6,0-8$ ). Since the initial size of the barnacles was similar among the locations (for crowded panels $F=1.42$, $\mathrm{df}=2,18, P=0.27$, for uncrowded panels $F=2.12$, $\mathrm{df}=2,18, P=0.15$ ), no correction for initial size was deemed necessary for this analysis. As with the previous analysis, differences were 
Table 1

Results of ANCOVA comparing effects of crowding among "front" individuals on the crowded and uncrowded, non-rotated panels

\begin{tabular}{|c|c|c|c|c|c|c|c|c|c|}
\hline \multirow[b]{2}{*}{ Variable } & \multicolumn{3}{|c|}{ Weeks $0-2$} & \multicolumn{3}{|c|}{ Weeks $0-4$} & \multicolumn{3}{|c|}{ Weeks $0-6$} \\
\hline & $\mathrm{df}$ & MS & $F$ & $\mathrm{df}$ & MS & $F$ & df & MS & $F$ \\
\hline Crowding (A) & 1 & 0.24 & 0.33 & 1 & 209.6 & $30.9 * * *$ & 1 & 192.9 & $11.3^{* *}$ \\
\hline Site (B) & 1 & 8.52 & $11.9 * *$ & 1 & 21.5 & 3.17 & 1 & 1.9 & 0.11 \\
\hline Initial size & 1 & 0.11 & 0.15 & 1 & 73.9 & $10.9 * *$ & 1 & 15.9 & 0.93 \\
\hline $\mathrm{A} \times \mathrm{B}$ & 1 & 0.37 & 0.52 & 1 & 31.4 & 4.62 & 1 & 8.13 & 0.48 \\
\hline Error & 9 & 0.72 & & 8 & 6.8 & & 7 & 17.02 & \\
\hline
\end{tabular}

Presented here is the reduced model; the interaction terms involving the covariate (initial size) were not significant, so they were eliminated. $* *=P<$ $0.01, * * *=P<0.001$.

calculated after first obtaining a single value for growth for each location on each panel.

The second analysis determined whether growth was a function of the number of upstream barnacles. Using the non-rotated panels, the individual farthest back in each row was identified, and the number of barnacles upstream of it was determined. This was done at the start and end of each 2-week interval, and the average was taken. (Note: for the first interval [week 0-2] only the number present at week 2 was used because, unfortunately, the appropriate data were not collected at week 0). This number was then compared against growth by using regression analysis. Separate analyses were done for the crowded and uncrowded panels for the first three intervals (weeks $0-2,2-4,4-6$ ), but they were combined for the last interval (week 6-8) because by then all barnacles had become uncrowded.

The effects of rotation were examined using two-way ANCOVA. This analysis was essentially the same as that used to test for competition for space. Treatment (rotated $v s$. non-rotated) and site (higher vs. lower current) were fixed factors, and initial size of the barnacle was used as the covariate. Comparisons were made for all four intervals (weeks $0-2,0-4,0-6,0-8$ ), and means per panel were calculated as previously described.

Chi-square analysis was used to look for differences in survivorship. As above, the effects of crowding were examined using the barnacles at the front of the crowded and uncrowded panels. The effects of competition for food were examined using those at the front and back of the uncrowded panels. Again, only the non-rotated panels were used.

\section{Results}

The comparison of growth at the front of the panels found that crowded individuals grew significantly less than uncrowded ones (Fig. 2, Table 1). On the uncrowded, nonrotated panels there were no significant differences in growth among locations (Fig. 2, Table 2), but there were significant, negative relationships between growth and the number of upstream barnacles (Fig. 3). In contrast, on the crowded, non-rotated panels there were significant differences in growth among locations (Fig. 2, Table 2), but there were no significant relationships between growth and the number of upstream barnacles (Fig. 3). There was no difference in growth between rotated and non-rotated individuals (Table 3).

Although crowded individuals had lower survivorship, the difference was only marginally significant (Fig. 4, $\chi^{2}=$ 3.04 , df $=1, P=0.08$ ). Survivorship was similar at the front and back of the uncrowded, non-rotated panels (Fig. 4, $\left.\chi^{2}=0.04, \mathrm{df}=1, P=0.85\right)$.

\section{Discussion}

Comparing competion for food and competion for space

Although the idea that filter feeders compete for food is not new (e.g., Moore, 1935; Barnes and Powell, 1950), more is known about the role of competition for space on rocky shores than about competition for food. This study was designed to decouple the effects of these two processes. Since the uncrowded barnacles could not compete for space, they were expected to grow more than the crowded indi-

Table 2

Difference in mean growth \pm 1 SE between front and back of the uncrowded, non-rotated panels

\begin{tabular}{ccccc}
\hline \hline Interval & Difference (Front-Back) & $t$ & df & $P$ \\
\hline Uncrowded & & & & \\
$0-2$ & $-0.04 \pm 0.05$ & -0.8 & 6 & 0.42 \\
$0-4$ & $-0.25 \pm 0.19$ & -1.3 & 5 & 0.24 \\
$0-6$ & $-0.13 \pm 0.20$ & -0.7 & 5 & 0.52 \\
$0-8$ & $-0.12 \pm 0.38$ & -0.3 & 4 & 0.76 \\
Crowded & & & & \\
$0-2$ & $-0.09 \pm 0.04$ & -2.2 & 6 & 0.07 \\
$0-4$ & $-0.56 \pm 0.06$ & -9.7 & 6 & $<0.001$ \\
$0-6$ & $-0.68 \pm 0.20$ & -3.5 & 4 & 0.03 \\
\hline
\end{tabular}

Results were compared against an expected value of 0 using paired $t$ test. 
Uncrowded

Crowded

Week $6-8$
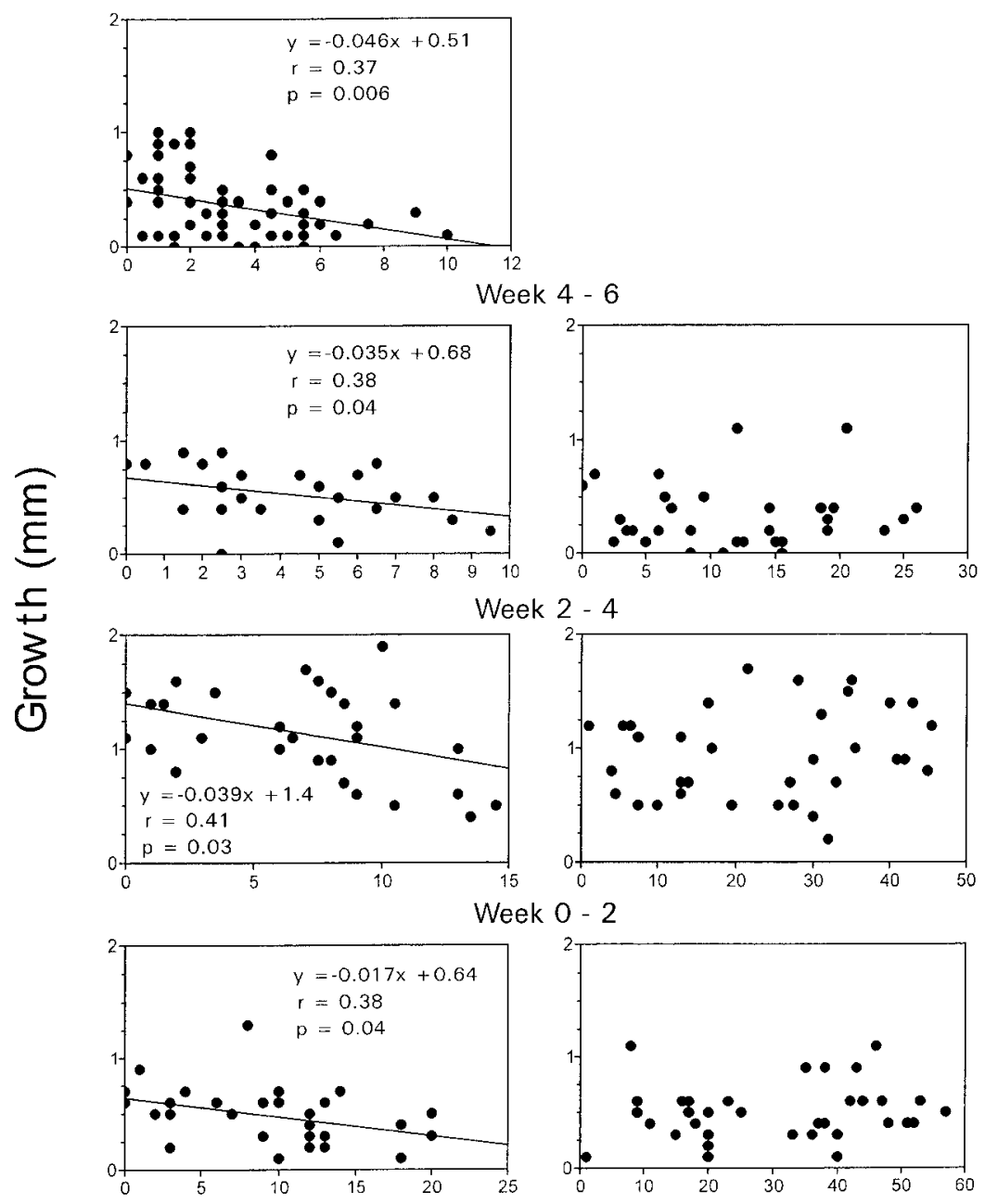

Number upstream barnacles

Figure 3. Relationship between growth and the number of upstream barnacles on the non-rotated panels.

viduals. Similarly, because the front of the wooden blocks always pointed upstream, the barnacles at the back of the blocks were expected to experience competition for food.

Overall, these predictions are supported by the results. For example, the crowded barnacles grew less than the uncrowded ones, a result found by many others (e.g., Connell, 1961a, b; Wu, 1980; Bertness, 1989). Furthermore, growth at the back of the panels was a function of the number of upstream barnacles, which is evidence of competition for food. However, this negative relationship was observed only on the uncrowded panels. Thus, competition for food was measurable only in the absence of competition for space, which suggests that it is the weaker of the two processes. This is further illustrated by the fact that the slopes of the regression lines were all quite shallow (Fig. 3). In fact, if the mean of the four slopes (mean $=-0.034 \mathrm{~mm}$ growth per upstream barnacle per interval) is used as an estimate of the strength of the effect, after 6 weeks an upstream barnacle would reduce the growth of its downstream neighbor by about $0.1 \mathrm{~mm}$. In comparison, after 6 weeks, crowding reduced growth by $1.1 \mathrm{~mm}$ (Fig. 2).

However, this does not mean that competition for food is unimportant. Since growth requires access to food, and adult barnacles compete for space only when they are growing, anything that affects the supply of food will ultimately affect the amount of competition for space. Although an individual's growth is apparently not much affected by the feeding of its immediate neighbors, competition for food is exploitation competition, unlike competition for space, which is interference competition. This means that individuals can be far apart and still interact, which makes competition for food a larger scale phenomenon than competi- 
Table 3

Results of ANCOVA testing the effects of rotation on growth at the back of the uncrowded panels

\begin{tabular}{|c|c|c|c|c|c|c|c|c|c|c|c|c|}
\hline \multirow[b]{2}{*}{ Source } & \multicolumn{3}{|c|}{ Weeks $0-2$} & \multicolumn{3}{|c|}{ Weeks $0-4$} & \multicolumn{3}{|c|}{ Weeks 0-6 } & \multicolumn{3}{|c|}{ Weeks $0-8$} \\
\hline & $\mathrm{df}$ & MS & $F$ & $\mathrm{df}$ & MS & $F$ & $\mathrm{df}$ & MS & $F$ & $\mathrm{df}$ & MS & $F$ \\
\hline Rotate (A) & 1 & 0.14 & 0.11 & 1 & 5.35 & 1.3 & 1 & 10.5 & 1.38 & 1 & 19.2 & 0.96 \\
\hline Site (B) & 1 & 3.14 & 2.4 & 1 & 3.44 & 0.81 & 1 & 0.56 & 0.074 & 1 & 0.01 & 0.000 \\
\hline Initial & 1 & 2.08 & 1.6 & 1 & 89.6 & $21.1^{* *}$ & 1 & 172.7 & $22.7 * * *$ & 1 & 186.3 & $9.27 *$ \\
\hline$A \times B$ & 1 & 0.80 & 0.61 & 1 & 0.34 & 0.08 & 1 & 0.747 & 0.098 & 1 & 0.81 & 0.04 \\
\hline Error & 9 & 1.31 & & 8 & 4.24 & & 8 & 7.62 & & 6 & 20.1 & \\
\hline
\end{tabular}

Presented here is the reduced model; the interaction terms involving the covariate (initial size) were not significant, so they were eliminated from the analyses. $*=P<0.05, * *=P<0.01$, *** $=P<0.001$.

tion for space. In fact, the results of the regression analyses suggest that with the addition of each upstream barnacle should come a small reduction in growth for those downstream. Thus, the cumulative effect of many upstream individuals could have important consequences for those downstream.

Despite the fact that upstream individuals take food from their downstream neighbors, growth on the crowded panels was greater at the back than at the front. Thus crowded individuals did better downstream, where they competed for both space and food, than upstream, where they only competed for space. There are three possible explanations for this result. First, previous studies have shown that when competition for space is severe, barnacles alter their morphology and grow taller instead of wider (Barnes and Powell, 1950; Bertness et al., 1998). Thus it is possible that, since growth is dependent upon food, those at the front of the panels experienced more intense competition for space than those at the back because more food was available at the front. If true, then most of the growth at the front of the

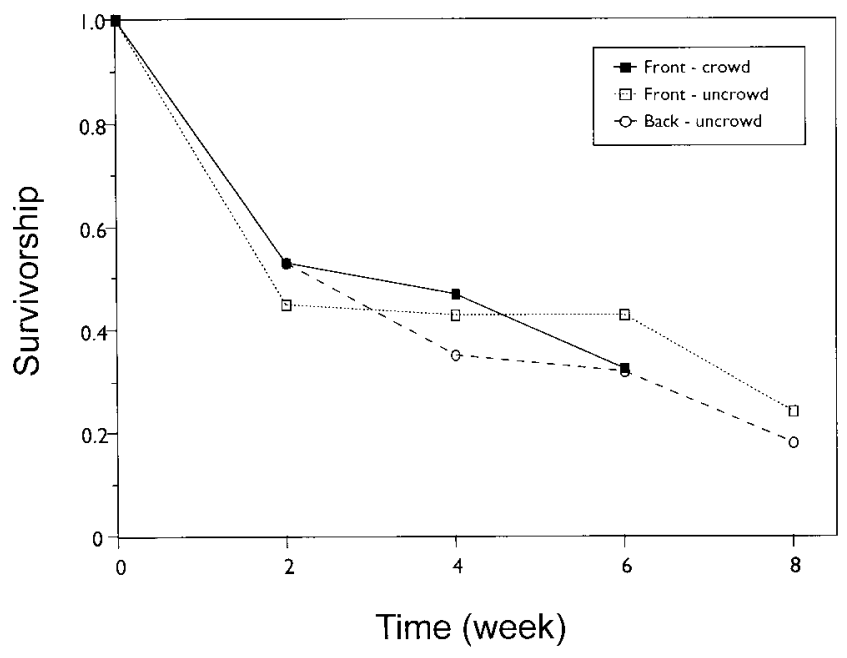

Figure 4. Survivorship of barnacles in the different treatments. panels would have been upwards, rather than outwards, resulting in barnacles that, for a given diameter, would be taller than those at the back. However, measurements of barnacles at both locations found little difference in their morphologies (Fig. 5). Therefore, this explanation seems unlikely.

It is also possible that growth was greater at the back of the panels because of the way the experiment was set up. Studies have shown that if the leading edge of the panel is not streamlined, a recirculating eddy can form at the front of the panel (Mullineaux and Butman, 1991; Mullineaux and Garland, 1993), which could cause individuals there to receive less food than those farther back. However, there are two reasons why this does not seem to be the correct explanation. First, the panels and blocks were beveled to minimize the chances of eddy formation. And second, if these recirculating eddies were indeed present, there should have also been a difference in growth among locations on

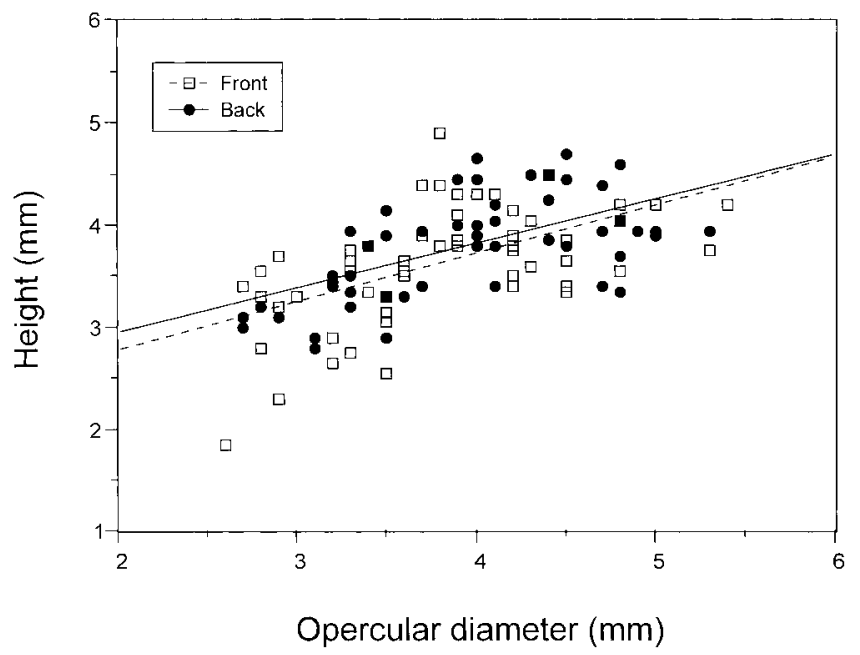

Figure 5. Relationship between the height and opercular diameter of barnacles at the front and back of the crowded panels measured at the end of the study. 
the uncrowded panels. Since there was not, this explanation also seems unlikely.

The third, and perhaps most likely, explanation for growth being greater at the back of the crowded panels is that those at the front were unable to feed efficiently because they were exposed to the full force of the current. This has been observed in bryozoans (Okamura, 1984, 1987; Eckman and Duggins, 1993) and in barnacles in currents as low as $10 \mathrm{~cm} / \mathrm{s}$ (Trager et al., 1994; however, see Eckman and Duggins, 1993). During the present study, current speeds as high as $35 \mathrm{~cm} / \mathrm{s}$ were measured (unpubl. data). As the current travels down the panel, drag would cause it to slow down, so barnacles farther downstream should feed more efficiently. The fact that growth in the middle of the panels was greater than at the front, but less than at the back, supports this idea (Fig. 1). That this was not observed on the uncrowded panels may be due to the fact that there were fewer barnacles on them to slow the current.

\section{Temporal changes in competition}

Over the course of the study, the barnacles on the crowded panels grew from about $2 \mathrm{~mm}$ basal diameter to $1-1.5 \mathrm{~cm}$. Since adjacent barnacles started out touching, this means that many more barnacles were initially present on the panels than could be supported as adults. Therefore, it is not surprising that competition for space was intense on these panels during the first few weeks. However, by week 6 , densities had been reduced so much by competition and predation that all crowded individuals had become uncrowded. Therefore, competition for space was no longer important, and for the first time competition for food became detectable on the crowded panels (Fig. 3, week 6-8).

This suggests that the type of competition barnacles like Balanus improvisus experience changes over the course of their life. During settlement, when cyprids cannot settle on occupied substrate, they may compete exploitatively for space (= preemption competition). Although the barnacles in this study did not experience this, several times during the study the panels became totally covered with new recruits. Thus, during the height of the settlement season, this type of competition may be severe. After settlement, interference competition for space is important. Eventually, as densities decrease, the effects of competition for space decline and the relative importance of competition for food increases.

Unless these ontogenetic changes were known, it would be possible to make erroneous conclusions about the importance of competition in structuring this community. For example, a study that used older individuals would probably conclude that competition for space was not important. However, this would underestimate the true importance of space competition, because this process is intense among young barnacles. Since similar ontogenetic changes undoubtedly take place for other species, this suggests that conclusions based on short-term experiments, which often focus on only one segment of an organism's life cycle, should be interpreted with caution.

\section{Conclusions}

Important resources for sessile filter feeders like barnacles include space and food. This study has shown how a barnacle's ability to utilize these resources is influenced by its neighbors. Immediate neighbors had little measurable impact on each other's food supply, but when crowded reduced each other's growth and survivorship through competition for space. In contrast, though distant neighbors cannot directly affect each other's access to space, they did so indirectly by affecting food availability. When uncrowded, upstream individuals reduced the growth of their downstream neighbors via competition for food. When crowded, however, they increased the growth of those downstream by increasing their feeding efficiency. Both such effects were not as great as those caused by competition for space with their immediate neighbors. Thus, the number (crowded $v s$. uncrowded), proximity (immediate $v s$. distant), and location (upstream vs. downstream) of an individual's neighbors have important consequences for its performance.

\section{Acknowledgments}

This study was conducted while I was a post-doctoral researcher at the Virginia Institute of Marine Science. Thanks go to Anthony Boxshall, Joe Connell, Amanda Maximchuk-Daly, Bob Diaz, Pete Raimondi, Eric Sanford, Sue Swarbrick, and Michelle Thompson for their help and comments.

\section{Literature Cited}

Barnes, H., and H. T. Powell. 1950. The development, general morphology, and subsequent elimination of barnacle populations, Balanus crenatus and B. balanoides, after a heavy initial settlement. J. Anim. Ecol. 19: 175-179.

Bertness, M. D. 1989. Intraspecific competition and facilitation in a northern acorn barnacle population. Ecology 70: 257-268.

Bertness, M. D., S. D. Gaines, and Su Ming Yeh. 1998. Making mountains out of barnacles: the dynamics of acorn barnacle hummocking. Ecology 79: 1382-1394.

Best, M. A., and J. P. Thorpe. 1986. Feeding-current interactions and competition for food among the bryozoan epiphytes of Fucus serratus. Mar. Biol. 93: 371-375.

Buss, L. W. 1979. Bryozoan overgrowth interactions-the interdependence of competition for space and food. Nature 281: 475-477.

Buss, L. W., and J. B. C. Jackson. 1981. Planktonic food availability and suspension-feeder abundance: evidence of in situ depletion. J. Exp. Mar. Biol. Ecol. 49: 151-161.

Connell, J. H. 1961a. Effects of competition, predation by Thais lapillus, and other factors on natural populations of the barnacle Balanus balanoides. Ecol. Monogr. 31: 61-104.

Connell, J. H. 1961b. The influence of interspecific competition and 
other factors on the distribution of the barnacle Chthamalus stellatus. Ecology 42: 710-723.

Cote, J., J. H. Himmelman, and M. R. Claereboudt. 1994. Separating effects of limited food and space on growth of the scallop Placopecten magellanicus in suspended culture. Mar. Ecol. Prog. Ser. 106: 85-91.

Crisp, D. J. 1964. An assessment of plankton grazing by barnacles. Pp. 251-264 in Grazing in Terrestrial and Marine Environments, D. J. Crisp, ed. Blackwell, Oxford.

Crisp, D. J., and H. Barnes. 1954. The orientation and distribution of barnacles at settlement with particular reference to surface contour. $J$. Anim. Ecol. 23: 142-162.

Crisp, D. J., and P. A. Davies. 1955. Observations in vivo on the breeding of Elminius modestus grown on glass slides. J. Mar. Biol. Assoc. UK 34: 357-380.

Eckman, J. E., and D. O. Duggins. 1993. Effects of flow speed on growth of benthic suspension feeders. Biol. Bull. 185: 28-41.

Frechette, M., and E. Bourget. 1985. Food-limited growth of Mytilus edulis in relation to the benthic boundary layer. Can. J. Fish. Aquat. Sci. 42: 1166-1170.

Frechette, M., and E. Despland. 1999. Impaired shell gaping and food depletion as mechanisms of asymmetric competition in mussels. Ecoscience 6: 1-11.

Frechette, M., and D. Lefaivre. 1990. Discriminating between food and space limitation in benthic suspension feeders using self-thinning relationships. Mar. Ecol. Prog. Ser. 65: 15-23.

Frechette, M., A. E. Aitken, and L. Page. 1992. Interdependence of food and space limitation of a benthic suspension feeder: consequences for self-thinning relationships. Mar. Ecol. Prog. Ser. 83: 55-62.

Glynn, P. W. 1973. Ecology of a Caribbean coral reef. The Porites reef-flat biotype: Part II. Plankton community with evidence for depletion. Mar. Biol. 22: 1-21.

Grime, J. P. 1979. Plant Strategies and Vegetation Processes. Wiley, Chichester.

Jorgensen, B. B. 1980. Seasonal oxygen depletion in the bottom waters of a Danish fjord and its effect on the benthic community. Oikos 34: $68-76$.

Levinton, J. 1972. Stability and trophic structure in deposit-feeding and suspension-feeding communities. Am. Nat. 106: 472-486.

Menge, B. A. 1976. Organization of New England rocky intertidal community - role of predation, competition, and environmental heterogeneity. Ecol. Monogr. 46: 355-393.

Moore, H. B. 1935. The biology of Balanus balanoides. IV. Relation to environmental factors. J. Mar. Biol. Assoc. U.K. 20: 279-307.
Mullineaux, L. S., and C. A. Butman. 1991. Initial contact, exploration and attachment of barnacle (Balanus amphitrite) cyprids settling in flow. Mar. Biol. 110: 93-103.

Mullineaux, L. S., and E. D. Garland. 1993. Larval recruitment in response to manipulated field flows. Mar. Biol. 116: 667-683.

Newell, C. R. 1990. The effects of mussel (Mytilus edulis, Linnaeus, 1758) position in seeded bottom patches on growth at subtidal lease sites in Maine. J. Shellfish Res. 8: 113-118.

Okamura, B. 1984. The effects of ambient flow velocity, colony size, and upstream colonies on the feeding success of Bryozoa. I. Bugula stolonifera Ryland, an arborescent species. J. Exp. Mar. Biol. Ecol. 83: 179-193.

Okamura, B. 1986. Group living and the effects of spatial position in aggregations of Mytilus edulis. Oecologia 69: 341-347.

Okamura, B. 1987. The effects of ambient flow velocity, colony size, and upstream colonies on the feeding success of Bryozoa. II. Conopeum reticulum (Linnaeus), an encrusting species. J. Exp. Mar. Biol. Ecol. 89: 69-80.

Page, H. M., and D. M. Hubbard. 1987. Temporal and spatial patterns of growth in mussels Mytilus edulis on an offshore platform: relationships to water temperature and food availability. J. Exp. Mar. Biol. Ecol. 111: 159-179.

Peterson, C. H. 1982. The importance of predation and intra- and interspecific competition in the population biology of two infaunal suspension-feeding bivalves, Protothaca staminea and Chione undatella. Ecol. Monogr. 52: 437-475.

Peterson, C. H. 1983. Interactions between two infaunal bivalves, Chione undatella (Sowerby) and Protothaca staminea (Conrad), and two potential enemies, Crepidula onyx Sowerby and Cancer anthonyi (Rathbun) J. Exp. Mar. Biol. Ecol. 68: 145-158.

Peterson, C. H., and R. Black. 1987. Resource depletion by active suspension feeders on tidal flats: influence of local density and tidal elevation. Limnol. Oceanogr. 32: 143-166.

Prins, T. C., V. Escaravage, A. C. Smaal, and J. C. H. Peeters. 1995. Nutrient cycling and phytoplankton dynamics in relation to mussel grazing in a mesocosm experiment. Ophelia 41: 289-315.

Trager, G., Y. Achituv, and A. Genin. 1994. Effects of prey escape ability, flow speed, and predator feeding mode on zooplankton capture by barnacles. Mar. Biol. 120: 251-259.

Wu, R. S. S. 1980. Effects of crowding on the energetics of the barnacle Balanus glandula Darwin. Can. J. Zool. 58: 559-566. 